\title{
A Design Method for the Roadside Clear Zone Based on Accident Simulation Analysis
}

\author{
Rui Cheng $(\mathbb{D}$, Ye Pan $(\mathbb{D}$, and Tao Wang \\ School of Architecture and Transportation, Guilin University of Electronic Technology, Guilin 541004, China \\ Correspondence should be addressed to Tao Wang; wangtao@seu.edu.cn
}

Received 15 July 2021; Accepted 26 October 2021; Published 25 November 2021

Academic Editor: Darong Huang

Copyright (c) 2021 Rui Cheng et al. This is an open access article distributed under the Creative Commons Attribution License, which permits unrestricted use, distribution, and reproduction in any medium, provided the original work is properly cited.

In order to improve the safety design of roadside areas and reduce the loss of roadside accidents, this paper uses PC-Crash software to perform an accident simulation analysis. By recording the track of the vehicle after entering the roadside, the recommended widths of the roadside clear zone for different operating speeds and horizontal curve radii in straight and curved sections are given. According to our previous research data, the conditions for setting the roadside clear zone are proposed. Finally, based on a cost-benefit ratio analysis, a comprehensive risk index method is adopted to evaluate the social stability risk of the project and conduct research on the design method of the roadside clear zone. The results show that the width of the roadside clear zone has an exponential relation with the departure speed and a power relation with the horizontal curve radius. The research results realize the accurate calculation of the roadside clear zone width and fill in the gaps of the relevant specifications and guidelines in the setting conditions of the roadside clear zone.

\section{Introduction}

Despite improvements in road safety, the "Global Status Report on Road Safety" issued by the World Health Organization shows that approximately 1.25 million people still die in traffic accidents yearly. In the twentieth century, approximately 25.85 million people died from traffic injuries worldwide, which is greater than the number of deaths in World War I. RISER, a European research project, has shown that roadside accidents account for $19 \%, 22 \%$, and $19 \%$ of the total accidents in Germany, Austria, and Greece, respectively, but account for $33 \%, 36 \%$, and $34 \%$ of all traffic fatalities, respectively [1]. According to the statistical report from the Roadside Safety Research Program of the Federal Highway Administration (FHWA), roadside accidents accounted for more than $50 \%$ of the total deaths in 2018 [2]. Additionally, the Road Traffic Accident Statistical Annual Report of China also revealed that roadside accidents accounted for approximately $8 \%$ of the total number of traffic accidents each year but had a $13 \%$ fatality rate [3]. Given the high death rate of roadside accidents, it is urgent to conduct research on roadside safety design.
Since the late 1960s, roadside safety design has been a hotly debated topic in highway design. The concept of the roadside clear zone (RCZ) first appeared in a meeting document of the Highway Research Board (HRB) in 1963, which was formally written into the Highway Safety Design Manual in May 1965. After two revisions in 1973 and 1978, the manual was incorporated into the practical application of road project construction. In 1989, the first edition of the Roadside Design Guide (RDG) was published by AASHTO, followed by the second edition in 2002, and the third and fourth editions were published in 2006 and 2011, respectively.

In the fourth edition of the RDG, the RCZ is defined as "Clear Zone-The unobstructed, traversable area provided beyond the edge of the through traveled way for the recovery of errant vehicles. The clear zone includes shoulders, bike lanes, and auxiliary lanes, except those auxiliary lanes that function such as through lanes" [4]. According to the definition of the $\mathrm{RCZ}$, this area should provide a fault-tolerance space with sufficient width, gentle slope, and no hazards for runaway vehicles. When implementing the RCZ design, how to mitigate existing hazards in the RCZ in order to reduce loss 
of out of control vehicles and how to determine the slope and width of the RCZ according to different road characteristics, regional characteristics, and traffic conditions have always been a topic of concern in academia.

The fourth edition of the RDG gives the recommended width of the RCZ in straight sections and the correction coefficient of the curved section. The recommended width of the RCZ in the straight section is determined based on the annual average daily traffic (AADT), design speed, slope gradient, and slope form (i.e., fill or cut) [4]. Meanwhile, this edition also gives the setting standard of the RCZ slope [4], as shown in Figure 1. A slope gradient equal to or less than 1: 4 is considered to be recoverable, and a slope gradient between 1:3 and 1:4 is considered to be unrecoverable. Additionally, when roadside conditions do not allow for setting a recoverable slope, an additional buffer zone (clear run-out zone) can be placed at the foot of the nonrecoverable slope to reduce accident losses, and it is stipulated that the slope gradient in this field should be equal to or less than 1:6. Note that these research results are widely used internationally. Given that the recommended widths from the fourth edition of the RDG are deduced based on limited empirical data, even though these empirical data provide a reference for roadside safety design in most countries, the road network characteristics, vehicle ownership, driver characteristics, roadside hazard distribution, and economic level of each country vary greatly. Therefore, scholars have taken various measures to analyze roadside safety design according to their national conditions.

China's Specifications for the Highway Safety Audit (JTG B05-2015) provides a graphic method for the RCZ width on fill and cut subgrades. The determination of the RCZ width in straight sections is based on the one-way AADT and running speed, and the RCZ width in the curved sections is selected by the correction coefficient according to operating speeds and the curve radii; furthermore, when the slope gradient is greater than 1:3.5, the filling slope cannot be considered to be an effective safe area; when the fill slope gradient is between 1:3.5 and 1:5.5, the 1/2 slope width can be regarded as a safe zone; when the slope gradient is less than 1:6, the entire slope width can be used as a safe clear zone [5]. Australian scholars have recommended that a clear area width of at least $2 \mathrm{~m}$ from the curb could significantly reduce injuries in vehicles leaving the road [6]. Sax et al. proposed that setting the RCZ at a width of $4 \sim 5$ feet could reduce collisions with roadside objects by $90 \%$ [7]. By analyzing the main factors influencing the design of the RCZ width, such as the braking reaction time, the distance traveled by vehicles, and the state of vehicles leaving the road, Fan and Xing constructed a calculation model of the RCZ width [8], where the basic assumption is that the slope is flat, which is not consistent with the actual state. The United Kingdom studied the relationship between the increase in the RCZ width and the number of accidents and found that increasing the RCZ width is correlated with a gradual decrease in the number of roadside accidents [9]. However, a study from Jurewicz and Pyta proposed that even an RCZ with a width of 29.5 feet still did not prevent numerous roadside accidents [10]. For this reason, in a study on driver behavior, by investigating the impact of two variables (i.e., the RCZ width and the density of roadside vegetation) on driver behavior from the perspective of vehicle speed and lateral position, Fitzpatrick et al. determined that the wider the RCZ, the faster the vehicle speed. As the RCZ width increases, drivers tend to drive closer to the edge of the road $[11,12]$.

In the setting method of the RCZ, a safety benefit-cost analysis system called ROADSIDE was developed by the first version of the RDG for roadside designers on specific sections [13]. Road design decision-makers need to weigh the risk of injury and death to traffic participants against the cost of installing and maintaining safety facilities. Based on the National Cooperative Highway Research Program (NCHRP) 22-9 and 22-9 (2) projects, the first Roadside Safety Analysis Program (RSAP) was developed to assess the effectiveness of roadside safety improvement after the publication of the RDG (2002 version). The RSAP is designed based on the method of "encroachment probability" and consists of two complete procedures: the user interface procedure, which provides a user-friendly environment for data input and results review, and the main analysis procedure, which includes benefit-cost procedures and algorithms. Compared with the ROADSIDE system, the RSAP has shown significant improvement in how encroachments and final crashes are allocated by using a random solution rather than a deterministic method [14].

Furthermore, Ayati and Shahidian proposed an optimal RCZ width by weighting the engineering costs and safety improvement benefits resulting from increasing the roadside area. The results show that for curves with a radius less than $195 \mathrm{~m}$, the wider roadside recovery zone is a key factor that affects roadside safety [15]. Considering the lack of land resources, Ayati and Shahidian implemented a reasonable allocation of limited resources among different roadside safety schemes in the form of charts through resource surveys [16]. According to the established chart, road design engineers could choose to install a guardrail or set a gentle embankment slope from the two aspects of roadside safety and economic safety. By proposing a series of traffic protection measures and considering various factors, including average collision cost, $\mathrm{AADT}$, and discount rate, Roque and Cardoso discussed the comprehensive safety benefits brought by implementing a variety of measures and the generated investment cost, operation cost, and maintenance cost. They then selected an alternative scheme according to the proposed incremental benefit-cost ratio [17].

In roadside safety design, there is a lack of discussion on a comprehensive consideration of benefits involving the roadside slope, which is not consistent with the actual state. In light of the lack of land resources and social stability problems that result from land requisition, the concept of a tolerance roadside design is impractical to effectively implement in all regions. Therefore, the RCZ should be set according to the land use indexes of different grade roads, the probability of roadside accidents, social stability, engineering costs, safety benefit, and so on. However, existing technical specifications, such as Technical Standards of Highway Engineering (JTG B01-2014) and Design 


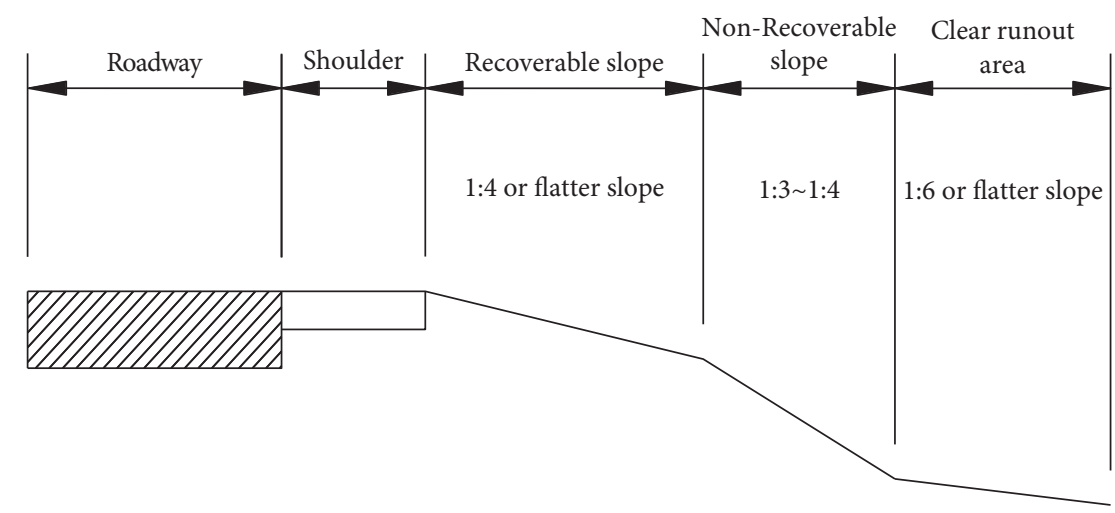

FIgURe 1: Setting standard of the RCZ slope.

Specification for Highway Alignment (JTG D20-2017) of China do not involve setting conditions for the RCZ. In addition, although China's Specifications for the Highway Safety Audit (JTG B05-2015) and the fourth edition of the RDG give a method for selecting the RCZ width in the curved section, they do not provide a theoretical basis. Therefore, in terms of the roadside safety design, there is still a lack of an accurate quantitative calculation of the RCZ width and the RCZ design method based on a benefit-cost analysis. How to develop a set of reasonable and effective methods for roadside safety design in order to reduce the frequency and severity of roadside accidents is an important research topic.

According to the research status and gaps of roadside safety, this paper uses PC-Crash software to conduct accident simulation analysis and proposes the recommended width of the RCZ in straight and curved sections for different operating speeds and curve radii by recording the vehicle's track after entering the roadside. Referring to our previous research results and data $[18,19]$, this paper utilizes a binary logistic regression analysis and multiple regression analyses to construct the probability prediction model of roadside accidents and an occupant injury risk assessment model. Based on the above research results and on the premise of considering the highway land use index, this paper puts forward the setting conditions for the RCZ, constructs the calculation model of the safety benefit brought by setting the RCZ, and gives the engineering cost calculation model from the two aspects of earthwork costs and land requisition costs. On the basis of a benefit-cost ratio analysis and the social stability risk assessment of a highway construction project, a set of RCZ design methods is therefore proposed in this paper.

\section{Calculation of the RCZ Width}

By analyzing the main factors influencing the design of the RCZ width, including the shoulder width, slope gradient, braking response time, departure speed, and departure angle, this paper uses the PC-Crash software to perform the simulation test. According to the track of vehicles after entering the roadside, the RCZ width is determined by calibrating the lateral distance between the right front of the vehicle and the edge of the carriageway.
2.1. Influence Factors. After a vehicle enters the roadside, most drivers will instinctively perform emergency braking, so the process of vehicles traveling can be equivalent to moving at a constant speed and moving at a uniform deceleration in kinematics. However, the distance required for a vehicle from the departure from the lane to a safe stop depends on a variety of factors, such as the shoulder width, slope gradient, braking response time, braking deceleration, departure speed, departure angle, and so on. Thus, before the simulation test, the values of the above factors should be discussed and analyzed.

2.1.1. Shoulder Width and Slope Gradient. The RCZ is generally composed of the shoulder and a gentle slope, so the width of the RCZ includes the shoulder width and the width of the slope clear zone (SCZ), as shown in Figure 2. The Specifications for Highway Safety Audit (JTG B05-2015) of China stipulates that when the slope gradient is less than 1:6, the entire slope width can be considered to be a safe area [5]. Therefore, this simulation test takes a slope gradient of 1:6 as the test condition when conducting research on the RCZ width. In addition, the shoulder width is determined in accordance with the relevant provisions in the Technical Standard of Highway Engineering (JTG B01-2014) [20].

2.1.2. Braking Response Time. The braking response time refers to the time required for the driver to identify the danger, the right foot to switch from the accelerator pedal to the brake pedal, and the vehicle to generate a braking force. Through an experimental detection of the drivers' decision time, Li et al. determined that most drivers' decision times are less than $0.5 \mathrm{~s}$, and $95 \%$ of drivers' decision times are less than $1.0 \mathrm{~s}$. When the driver identifies the danger, it takes approximately $0.2 \mathrm{~s}$ for the right foot to move from the accelerator pedal to the brake pedal and approximately $0.1 \mathrm{~s}$ from when the brake pedal is pressed to when the vehicle begins braking [21]. Therefore, the braking response time is approximately $0.8 \mathrm{~s}-1.3 \mathrm{~s}$.

2.1.3. Braking Deceleration. The braking deceleration taken by drivers in the face of emergencies is greatly affected by the adhesion coefficient, which mainly depends on the road 


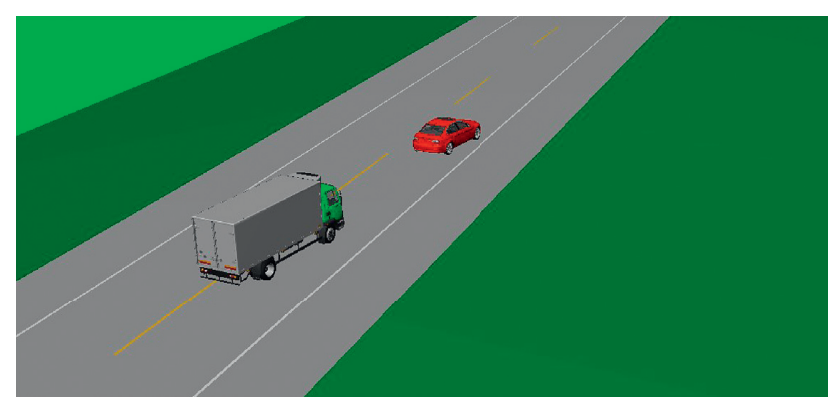

Figure 2: Test scenario.

material and road conditions. According to the stipulation of identification for the speed of vehicle involved in road traffic accident, a hard shoulder is generally asphalt pavement with an adhesion coefficient of 0.7; a dirt shoulder is generally sandy soil or soil; and its adhesion coefficient can be set at 0.55 [22]. Since most of the slope surface is covered by vegetation and the moisture content will affect the soil strength and make its adhesion coefficient change, so 0.55 can be used under dry soil conditions.

2.1.4. Departure Speed and Departure Angle. Many factors determine the angle of the vehicle leaving the lane. Most drivers will suddenly turn the steering wheel once they recognize danger. Therefore, the actual departure angle of the vehicle is of great randomness and uncertainty, which cannot be calculated quantitatively. Since there is currently no relevant research in China, according to the European RISER project on the relationship between vehicle departure angles and departure speeds in actual roadside accidents [1], the departure angles corresponding to different departure speeds can be approximately estimated, as shown in Table 1 .

2.2. Simulation Test. PC-Crash is a computer simulation software developed by Austrian scholars. With powerful functions and a simple operation, this software is widely used in the world for simulations and reconstruction analyses of traffic accidents. PC-Crash software is based on the theory of energy conservation, momentum conservation, and Newton's three laws and combines the vehicle's rigid body, the road, and a multirigid body module to build the vehicle collision simulation model, which has the following advantages: (1) it allows vehicles to enter the roadside; (2) it contributes to achieving quantitative and accurate calculation of RCZ width on the basis of the assigned variables and distance calibration function; and (3) it is widely used in forensic identification and liability determination of traffic accidents, so it can recreate the accident process more realistically. For example, Cheng et al. carried out the test of a vehicle entering the roadside by $\mathrm{PC}$-Crash software and predicted the probability of roadside accidents for curved sections on highways [18]. Zou et al. used PC-Crash to reconstruct freely available real-world vehicle-pedestrian video collisions and explored the cause mechanism of pedestrian injuries [23]. Wu et al. utilized a multibody system model in PC-Crash to reconstruct the elderly vulnerable road users' kinematics and head injuries [24]. These studies
TABle 1: Departure angle.

\begin{tabular}{lccccccccc}
\hline Variable & \multicolumn{11}{c}{ Value } \\
\hline $\begin{array}{l}\text { Departure speed } \\
\left(\mathrm{km} \cdot \mathrm{h}^{-1}\right)\end{array}$ & 40 & 50 & 60 & 70 & 80 & 90 & 100 & 110 & 120 \\
Departure angle $\left(^{\circ}\right)$ & 12 & 10 & 9 & 8 & 7 & 6 & 5 & 5 & 4 \\
\hline
\end{tabular}

have proven that PC-Crash software has high accuracy in simulating traffic accidents.

2.2.1. Test Scenario Construction. To improve the reliability of the research results, before the simulation test, we selected a case of a roadside accident to calibrate the simulation scene of the PC-Crash software. The accident section is a two-way four-lane road with a lane width of $3.75 \mathrm{~m}$, a shoulder width of $3 \mathrm{~m}$, a horizontal curve radius of $600 \mathrm{~m}$, a slope gradient of $1: 6$, a subgrade height of $0.7 \mathrm{~m}$, dry asphalt pavement, and a slope covered with vegetation. According to traces at the accident scene, the departure angle of the vehicle was approximately $6^{\circ}$, and the departure distance was approximately $44.3 \mathrm{~m}$. These findings, combined with the driver's confession, indicate that the vehicle speed was approximately $90 \mathrm{~km} / \mathrm{h}$. After the vehicle entered the roadside, the driver braked and took a slight left turn, as shown in Figure 3(a). PC-Crash software is first used to construct the road model, and various road parameters are set according to the characteristics of the accident section, with the adhesion coefficients of the road and slope set as 0.7 and 0.55 , respectively. Subsequently, the test vehicle conforming to the accident vehicle is selected from the simulation software, and the speed, departure angle, braking, and steering of the test vehicle are set according to the accident information, with the braking response time set as $1.3 \mathrm{~s}$. Finally, the simulation results show that the departure distance of the test vehicle is approximately $44.5 \mathrm{~m}$, and its stop position and pose are basically consistent with those of the accident vehicle (as shown in Figure 3(b)). The effectiveness of the simulation scene is therefore verified.

According to the calibrated simulation scene, for straight sections, this paper uses PC-Crash to establish a two-way two-lane road model with a lane width of $3.75 \mathrm{~m}$, a slope gradient of 1:6, and a shoulder width of $3 \mathrm{~m}$. For the curved section, referring to the Design Specification for Highway Alignment (JTG D20-2017) [25], the horizontal curve radius is set as $200 \mathrm{~m}, 300 \mathrm{~m}, 400 \mathrm{~m}, 500 \mathrm{~m}$, and $600 \mathrm{~m}$ based on the above road model. BMW-116d Autom and ASCHERSLEBEN KAROSS are selected as the representative models for the car and truck, respectively, and their parameters are set in accordance with the literature $[18,19]$. The constructed test scenario is shown in Figure 2.

The vehicle fully brakes by setting the simulation motion sequence module. The braking response times are set at $0.8 \mathrm{~s}$ and $1.3 \mathrm{~s}$, and the departure speeds are set as $50 \mathrm{~km} / \mathrm{h}, 60 \mathrm{~km} /$ $\mathrm{h}, 70 \mathrm{~km} / \mathrm{h}, 80 \mathrm{~km} / \mathrm{h}, 90 \mathrm{~km} / \mathrm{h}, 100 \mathrm{~km} / \mathrm{h}, 110 \mathrm{~km} / \mathrm{h}$, and $120 \mathrm{~km} / \mathrm{h}$. The departure angle is set according to Table 1 .

2.2.2. Test Process. According to the above variable values, $2 \times 8=16$ test conditions can be constructed. In order to ensure the accuracy of the simulation results, each vehicle 


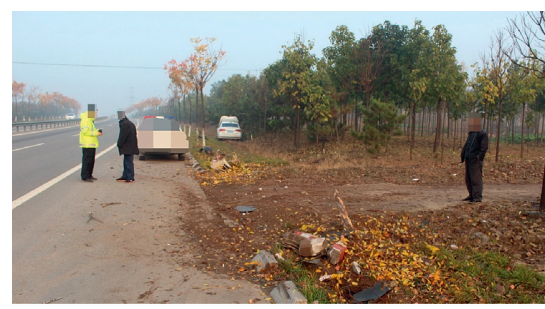

(a)

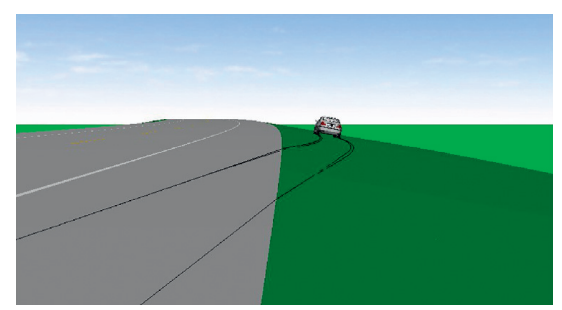

(b)

FIgURE 3: Simulation calibration: (a) accident scene and (b) simulation scene.

type is simulated repeatedly 5 times under each test condition. The two vehicle types could be simulated 10 times, and the average value of the results is finally calculated. After each simulation, the ranging tool of PCCrash software is used to measure the lateral distance between the right front of the vehicle and the road edge, that is, the guaranteed width of the SCZ. Combined with the shoulder width of a specific section, the recommended width of the RCZ can be obtained, as shown in Figure 4 .

2.3. Recommended RCZ Width. According to the above test process, $2 \times 8 \times 10=160$ simulation tests are conducted in the straight section, and $2 \times 8 \times 10 \times 5=800$ simulation tests are conducted in the curved section. When determining the standard of the RCZ width, the vehicle departure speed should take the operating speed as the basis, rather than the design speed.

2.3.1. RCZ Width in the Straight Section. By calculating the average value of the test results under different test conditions, for the straight section, Table 2 gives the recommended width of the RCZ corresponding to eight operating speeds when the shoulder width is $3 \mathrm{~m}$. The upper and lower limits of the RCZ width in Table 2 are the measured average values corresponding to brake response times of $0.8 \mathrm{~s}$ and $1.3 \mathrm{~s}$, respectively. The upper limit should be taken into consideration when the road designer sets the RCZ, which can significantly improve the roadside safety level. Since the driver's basic braking response time is $0.8 \mathrm{~s}$, the setting of the RCZ should at least meet the requirements of the lower limits.

2.3.2. RCZ Width in the Curved Section. For the curved section, according to the collected simulation data, Figures 5 and 6 show the relationships between the departure speed and the SCZ width and between the horizontal curve radius and the SCZ width, respectively. As can be seen from Figure 5, with an increase in the departure speed, the width of the SCZ gradually increases, and the increasing amplitude becomes larger and larger; the width tends to be dispersed from concentration. It can be seen from Figure 6 that with an increase in the horizontal curve, the width of the SCZ gradually decreases, and the decreasing amplitude becomes smaller and smaller; the width tends to be concentrated from dispersion.
Referring to the trends analysis of the departure speed, the horizontal curve radius, and the SCZ width, SPSS software is used to fit the calculation models of the lower and upper limits of the RCZ width $m$ in the curve segment, as shown in Table 3 . The correlation coefficient $R^{2}$ is usually used to test the fitting goodness of the model; its value is between 0 and 1 . The higher the $R^{2}$ is, the better the fitting goodness of the model is, that is, the stronger the ability of the model is to explain the dependent variable. By comparing the $R^{2}$ of different models, models (b) and (f) are the optimal models for the lower and upper limit value of the RCZ width, respectively. As can be seen from these two optimal models, the width of the RCZ has an exponential relation with the departure speed and a power relation with the horizontal curve radius.

\section{Setting Conditions for the RCZ}

3.1. Overall Framework. This paper considers the limitations of the highway land use index (related to the land scope of the SCZ $l$ ). According to the subgrade height $h$ and shoulder width $w$ and combined with the recommended width $m$ of the RCZ obtained from this paper, the setting conditions of the RCZ are studied. For sections equipped with the RCZ setting conditions, based on our previous research results and data, the probability model of roadside accident occurrence and the occupant injury risk assessment model are first fitted; then the calculation model of the safety improvement benefit brought by the RCZ is constructed. Finally, the engineering cost caused by the RCZ is calculated from the two aspects of earthwork costs and land requisition costs. If the benefit-cost ratio is great than 1 , then the social stability risk generated by setting the RCZ is further evaluated. If the social stability risk is less than 0.36 , it is recommended that the RCZ be set; otherwise, it is unadvisable to set the RCZ. The design idea of the RCZ is shown in Figure 7 .

Given the shortage of land resources and the limitation of a land acquisition index in China, it is difficult to realize the design of the RCZ in all regions. Therefore, before setting the RCZ, it is necessary to consider whether the conditions for setting the RCZ are available on the roadside. According to the relevant provisions of the Specifications for Highway Safety Audit (JTG B05-2015), when the slope gradient is 1:6 or lower, the entire slope width can be used as a safe clear zone [5]. Therefore, $h$ and $l$ should satisfy the following relationship: 


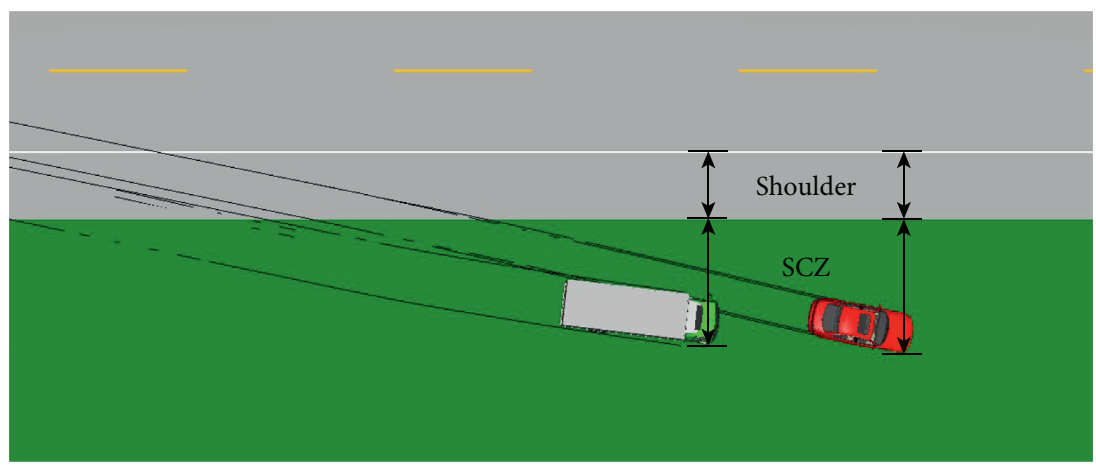

Figure 4: Definition of the RCZ width.

TABLE 2: Recommended width of the RCZ in the straight section where the shoulder width is $3 \mathrm{~m}$.

\begin{tabular}{lc}
\hline Operating speed $\left(\mathrm{km} \cdot \mathrm{h}^{-1}\right)$ & Recommended width of the RCZ $(\mathrm{m})$ \\
\hline 50 & $3.085(0.085) \sim 3.098(0.098)$ \\
60 & $4.055(1.055) \sim 4.168(1.168)$ \\
70 & $5.2001(2.001) \sim 5.260(2.260)$ \\
80 & $5.795(2.795) \sim 6.052(3.052)$ \\
90 & $6.380(3.380) \sim 6.507(3.507)$ \\
100 & $6.610(3.610) \sim 7.201(4.201)$ \\
110 & $8.355(5.355) \sim 9.420(6.420)$ \\
120 & $9.645(6.645) \sim 11.532(8.532)$ \\
\hline
\end{tabular}

Note. The width of the SCZ is in brackets. When setting the RCZ, the width of the RCZ can be determined according to different shoulder widths.

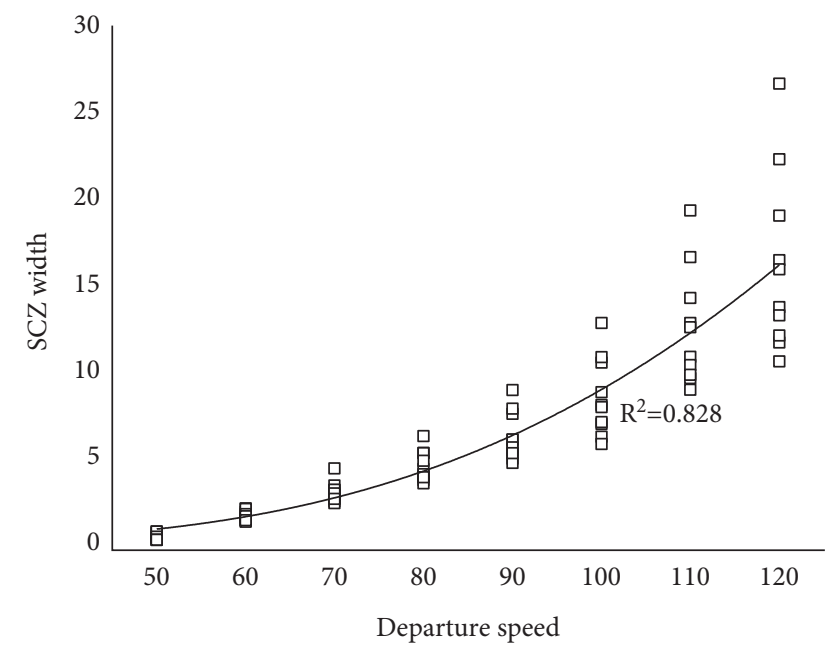

FIGURE 5: Relationship between the SCZ width and departure speed.

$$
\frac{h}{l} \leq 1: 6 \approx 0.167
$$

where $l$ depends on the highway land scope $L$, which is composed of the subgrade width $W$ (including $w$ ), $l$, the berm width $l_{1}$, the width of side ditch $l_{2}$, and the width of the outer area of side ditch $l_{3}$, as shown in Figure 8. According to the provisions of China's Highway Engineering Project Construction Land Index (Construction Standard [2018] 124) [26] and Design Specification for Highway Alignment

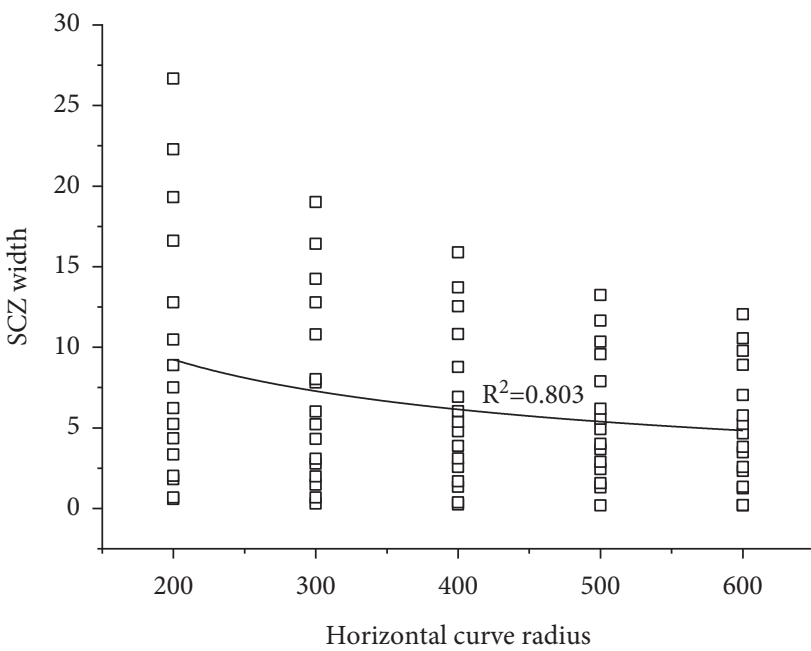

Figure 6: Relationship between the SCZ width and horizontal curve radius.

(JTG D20-2017) [25], for the subgrade width and land scope corresponding to highways of different grades, $l$ can be calculated as follows:

$$
l=\frac{L-W-l_{1}-l_{2}-l_{3}}{2} .
$$

In practical engineering implementations, the land scope of the highway is often limited due to the impact of structures or residential areas along the road, and it is difficult to fully comply with the regulations. Therefore, the actual land scope should be determined according to the specific conditions on the roadside. In addition, in the case of conforming to formula (1), the RCZ should also meet the following relationships:

$$
l+w \geq \text { lower limit value of } m .
$$

That is, the RCZ width should not be less than the lower limit of the recommended RCZ width obtained in Section 2.

3.2. Safety Benefit Calculation Model. Although the RCZ can bring considerable traffic safety benefits, given that the setting of the RCZ will generate additional engineering costs and land requisition costs, setting the RCZ should be considered on the basis of measuring safety benefits and 
TABle 3: Model building.

\begin{tabular}{lccc}
\hline No. & Models & $R^{2}$ \\
\hline a & & $m=1.05 \times 10^{-5} v^{3}-0.032 R-3.49 \times 10^{-14} R^{2}+w$ & 0.674 \\
$\mathrm{~b}$ & & $m=387.49 e^{-(395.448 /(v-1.44))}+5.027 \times 10^{6}(1+R)^{-2.669}+w$ & 0.919 \\
$\mathrm{c}$ & Lower limit value (braking reaction time is $0.8 \mathrm{~s})$ & $m=0.003 v^{2}-0.208 v-70.717(1+R)^{0.044}+96+w$ & 0.790 \\
$\mathrm{~d}$ & & $m=-2.786 e^{-0.013 v}-0.029 R+2.339 \times 10^{-5} R^{2}+w$ & 0.587 \\
$\mathrm{e}$ & & $m=-7.09 \times 10^{5} e^{\left(2.3 \times 10^{4}\right) /\left(v-2.7 \times 10^{3}\right)}-0.035 R+2.62 \times 10^{-5} R^{2}+w$ & 0.864 \\
\hline $\mathrm{f}$ & & $m=284.711 e^{-(314.869 /(v-11.273))}+2.888 \times 10^{6}(1+R)^{-2.52}+w$ & 0.911 \\
$\mathrm{~g}$ & & $m=1.06 \times 10^{-5} v^{3}-83.34(1+R)^{0.038}+104.18+w$ & 0.857 \\
$\mathrm{~h}$ & Upper limit value (braking reaction time is $1.3 \mathrm{~s})$ & $m=0.0025 v^{2}-0.204 v-0.032 R+2.644 \times 10^{-5} R^{2}+12.747+w$ & 0.898 \\
$\mathrm{i}$ & & $m=21.442 e^{-(86.63 / v)}-0.033 R+2.654 \times 10^{-5} R^{2}+w$ & 0.593 \\
$\mathrm{j}$ & & $m=-12.25 e^{-22.95 v}-1.75 \times 10^{-8} R^{3}+8.121+w$ & 0.479 \\
\hline
\end{tabular}

Note. $v$ is the departure speed, $\mathrm{km} \cdot \mathrm{h}^{-1} ; R$ refers to the horizontal curve radius, $\mathrm{m}$; and $w$ presents the shoulder width, $\mathrm{m}$.

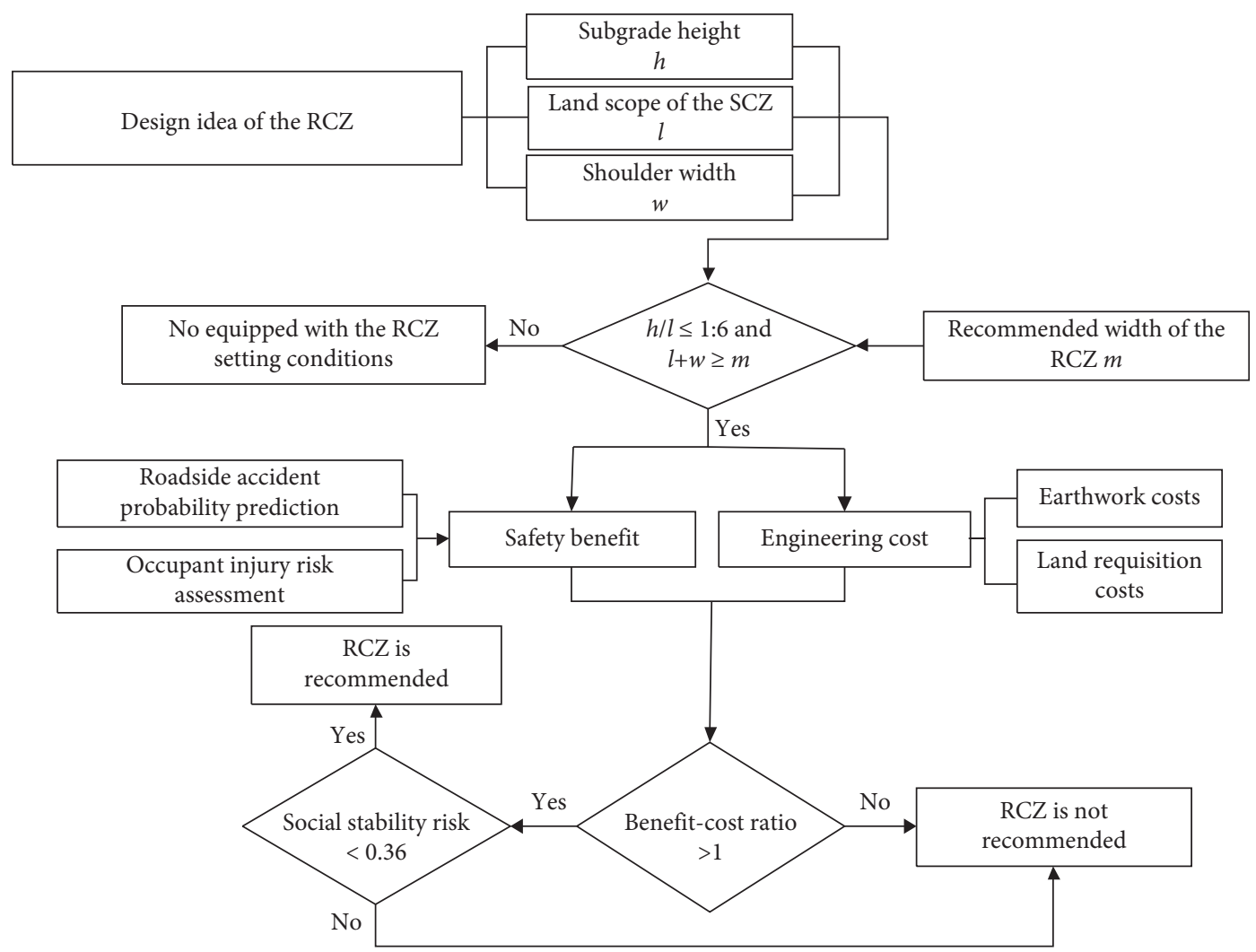

Figure 7: Design idea of the RCZ.

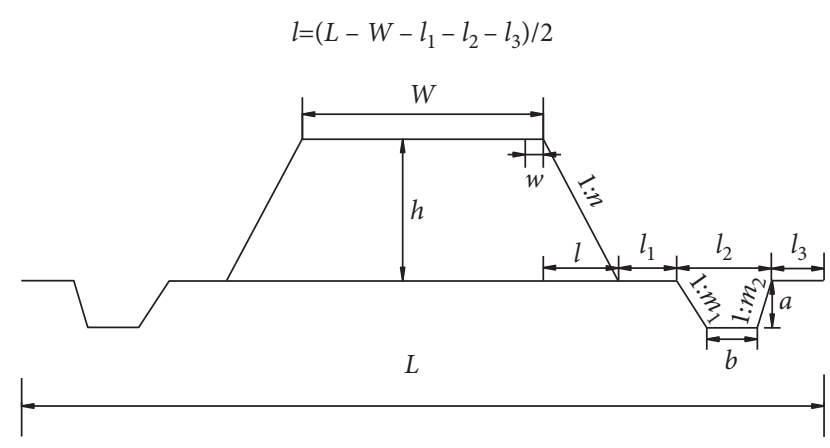

Figure 8: Highway land scope. engineering costs for sections equipped with the RCZ setting conditions. If the benefit-cost ratio is great than 1 , it can be further considered when setting the RCZ. In addition, when determining the probability prediction of roadside accidents and the occupant injury risk assessment, this paper uniformly collates and analyzes the accident data of different vehicle types from two studies $[18,19]$ in order to obtain the applicability of the research results to different vehicle types.

3.2.1. Probability Prediction of Roadside Accidents. Based on the obtained 12,800 roadside accident data and the identified significant risk factors (i.e., departure speed, horizontal 
curve radius, vehicle type, adhesion coefficient, and shoulder width) by us in the early stage (see the literature [18]). This paper uses a binary logistic regression analysis to construct a probability prediction model of roadside accidents involving the horizontal curve radius, shoulder width, adhesion coefficient, and departure speed.

(1) Model Building. According to the obtained data of roadside accidents, this paper takes the occurrence of roadside accidents as the dependent variable, which is divided into two grades: $y=1$ (roadside accidents occur) and $y=2$ (no roadside accidents occur). It then takes the departure speed $v$, horizontal curve radius $R$, shoulder width $w$, and adhesion coefficient $\mu$ as independent variables and uses SPSS software to perform a binary logistic regression analysis, as shown in Table 4.
It can be seen from Table 4 that the above four variables are significantly correlated with the occurrence of roadside accidents. The following regression equation can be constructed according to the parameter estimates:

$$
\ln \left(\frac{P_{1}}{P_{2}}\right)=-4.085+0.078 v-2.7 \times 10^{-4} R-4.011 \mu-1.515 w
$$

where $P_{1}$ and $P_{2}$ are the prediction probabilities of occurrence and nonoccurrence of roadside accidents, respectively. Formula (4) can be converted into the cumulative logistic probability prediction model, which represents the occurrence of roadside accidents:

$$
P(y \leq 1)=\frac{\exp \left(-4.085+0.078 v-2.7 \times 10^{-4} R-4.011 \mu-1.515 w\right)}{1+\exp \left(-4.085+0.078 v-2.7 \times 10^{-4} R-4.011 \mu-1.515 w\right)}
$$

Model (5) is mainly used to predict the probability of roadside accidents in the curved section. It is stipulated in the Design Specification for Highway Alignment (JTG D202017) that the maximum radius of the curve should not exceed $10,000 \mathrm{~m}$ [25]. In order to realize the probability prediction of roadside accidents in the straight section, this paper defines that model (5) is applicable to a straight segment when $R$ is set as $10,000 \mathrm{~m}$.

(2) Model Verification. According to the model prediction results, the ROC curve is drawn using SPSS software, as shown in Figure 9. As can be seen from Figure 9, the ROC curve is very close to the upper left corner, and the area under the curve (AUC) is $0.969>0.9$, indicating that the fitting effect of the probability prediction model of roadside accidents is good, with a confidence level of $95 \%$.

3.2.2. Risk Assessment of Occupant Injuries in Roadside Accidents. Based on our previous collected 1,500 data of roadside accidents (see the literature [19]), by considering the departure speed, horizontal curve radius, slope gradient, and subgrade height, this paper uses multiple regression analyses to fit the occupant injury risk assessment model of roadside accidents based on the acceleration severity index (ASI) and utilizes a Fisher optimal segmentation method to rationally classify the occupant injury risk levels.

(1) Model Building. According to the relationships between the ASI and various risk factors explored in the literature [19], by comparing the correlation coefficients $R^{2}$ of different models, the optimal model of the occupant injury risk assessment for the straight and curved sections are respectively fitted as follows:

Straight section:

$\mathrm{ASI}=0.008 v+0.123 h+4.76 \times 10^{-5} e^{0.033 \alpha}+0.876$

Curved section:

$$
\mathrm{ASI}=0.01 v+0.127 h+0.306 e^{0.0419 \alpha}+7.832 R^{-0.165}-2.392 \text {, }
$$

where $\alpha$ is the slope gradient, ${ }^{\circ}$. Among them, the correlation coefficient $R^{2}$ of model (6) is 0.976 , and that of model (7) is 0.963 .

(2) Classification of Occupant Injury Risk. This paper uses a Fisher optimal segmentation algorithm to classify the ASI data in order to obtain the classification scheme of roadside accidents risk, including the optimal number of classifications and the corresponding threshold of each level. Fisher's principle of optimal segmentation is to ensure a minimum sum of squares of the intragroup deviation of the segmented ordered sample data, and the corresponding group has optimal segmentation.

Based on the 1,200 data groups obtained from the literature [19], the data for ASI $\leq 1$ are screened as a group, and the risk is set to level I. The remaining 269 groups of data are numbered by the order of the ASI values from small to large to generate ASI-ordered samples, which are denoted as $x_{i}$ $(i=1,2, \ldots, 269)$. For the specific segmentation steps of ordered samples, refer to the literature [19]. The algorithm code is written by MATLAB software to calculate the category diameter and minimum error function of the ordered sample, and the curve of the minimum error function with different classification numbers $k$ is drawn, as shown in Figure 10. 
TABLE 4: Estimate of the parameters.

\begin{tabular}{|c|c|c|c|c|c|}
\hline Variable & Parameter & Standard deviation & Wald & Degree of freedom & Significance \\
\hline Departure speed & 0.078 & 0.003 & 1,877 & 1 & $<0.01$ \\
\hline Horizontal curve radius & $-2.7 e-04$ & 0.001 & 1,749 & 1 & $<0.01$ \\
\hline Adhesion coefficient & -4.011 & 0.186 & 466 & 1 & $<0.01$ \\
\hline Shoulder width & -1.515 & 0.073 & 434 & 1 & $<0.01$ \\
\hline Constant & -4.085 & 0.211 & 373 & 1 & $<0.01$ \\
\hline
\end{tabular}

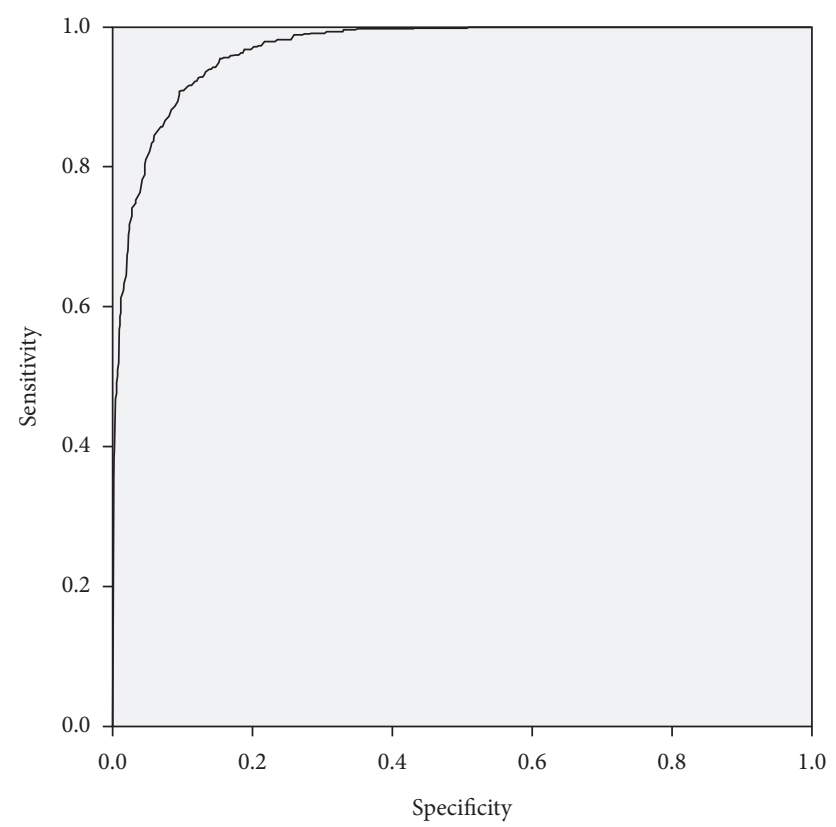

Figure 9: ROC curve.

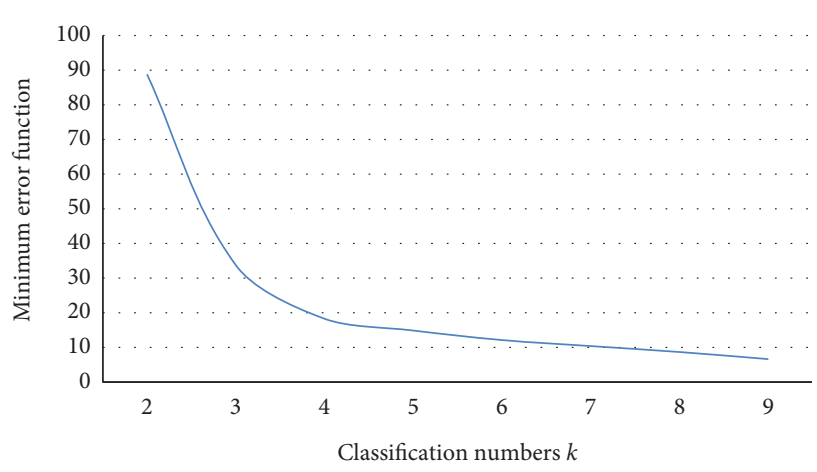

FIgURE 10: Relationship between the minimum error function and classification number.

As shown in Figure 10, when $k=3$ and 4 , the curvature of the ordered sample significantly varies. To further determine the optimal classification number, the ratios of the minimum error function $\beta(k)$ of the adjacent classification number are calculated in Table 5 .

According to Table $5, \beta$ (3) is greater than $\beta$ (4). Thus, $k=3$ is the optimal classification number for the ordered samples. Additionally, the codes that correspond to the optimal classification can be obtained from Table 5, so the corresponding injury index threshold can be determined. Based on the above research results and considering the classification of occupant injuries in traffic accidents in China, the criteria for the occupant injury risk assessment are proposed, as shown in Table 6 .

\subsubsection{Safety Improvement Benefit Calculation}

(1) Number of Roadside Accidents. According to the probability prediction model of roadside accidents constructed in Section 3.2.1, the following prediction model of the number of roadside accidents is proposed by introducing AADT:

$$
A=\operatorname{AADT}\left(\frac{\exp \left(-4.085+0.078 v-2.7 \times 10^{-4} R-4.011 \mu-1.515 w\right)}{1+\exp \left(-4.085+0.078 v-2.7 \times 10^{-4} R-4.011 \mu-1.515 w\right)}\right)
$$


TABLe 5: Classification results.

\begin{tabular}{cccc}
\hline$k$ & Minimum error function & Classification & $\beta$ \\
\hline 2 & 88.675 & $\{1 \sim 156\}\{157 \sim 269\}$ & - \\
3 & 32.521 & $\{1 \sim 89\}\{90 \sim 156\}\{157 \sim 269\}$ & 1.74 \\
4 & 18.671 & $\{1 \sim 43\}\{44 \sim 89\}\{90 \sim 156\}\{157 \sim 269\}$ & \\
5 & 15.013 & $\{1 \sim 43\}\{44 \sim 89\}\{90 \sim 156\}\{157 \sim 202\}\{203 \sim 269\}$ & 1.24 \\
\hline
\end{tabular}

TABLE 6: Criteria for the occupant injury risk assessment.

\begin{tabular}{lcc}
\hline Risk level & ASI threshold value & Occupant injury level \\
\hline I & $\leq 1$ & Noninjury \\
II & $(1,1.31]$ & Moderate injury \\
III & $(1.31,1.78]$ & Disabling injury \\
IV & $>1.78$ & Fatal injury \\
\hline
\end{tabular}

where $A$ is the number of roadside accidents.

(2) Reduction of Occupant Injuries per Accident Brought by the RCZ. The reduction of occupant injuries brought by setting the RCZ can be calculated quantitatively by the occupant injury risk level, that is: occupant injury risk level without setting the RCZ - the occupant injury risk level with setting the RCZ. Since setting the RCZ can effectively avoid the occurrence of roadside accidents, this paper assumes that the setting of the RCZ will not cause casualties of passengers in roadside accidents, that is, the risk is level I (as shown in Table 6). Therefore, the reduction of the occupant injuries per accident brought by the RCZ can be equivalent to the occupant injury risk level per accident without setting the RCZ, which can be obtained according to the occupant injury risk assessment model constructed in Section 3.2.2. Additionally, according to the Specifications for Highway Safety Audit (JTG B05-2015), when the slope gradient is steeper than 1:3.5, it cannot be regarded as an effective safety clear zone [5]. Therefore, this paper takes the slope gradient of 1:3.5 as the basic index for not setting the RCZ.

(3) Standard Economic Losses per Accident at Different Occupant Injury Risk Levels. There are currently few studies on the statistics of casualties, medical compensation, and property losses of traffic accidents in China. Therefore, this paper collects a total of 347 economic losses of casualties in traffic accidents of different severity via a questionnaire survey and telephone inquiry among lawyers, traffic polices, and insurance practitioners, as shown in Table 7. According to the statistical analysis, the average economic loss of moderate injury per accident is approximately 60,000 yuan; the average economic loss of disabling injury per accident is approximately 120,000 yuan; and the economic loss of fatal injuries per accident is approximately 370,000 yuan.

Based on the above analysis, the calculation model for a safety improvement benefit brought by setting the RCZ is given as follows: AADT $\times$ the occurrence probability of roadside accidents $\times$ reduction in occupant injuries per accident brought by the $\mathrm{RCZ} \times$ standard economic losses per accident at different occupant injury risk levels.
3.3. Engineering Cost Calculation Model. By establishing the calculation models of earthwork costs and land requisition costs, this paper calculates the difference in the economic costs with and without the RCZ in order to obtain the additional engineering costs caused by setting the RCZ.

3.3.1. Earthwork Costs. It is assumed that the slope gradient is $1: n_{1}$ in case the roadside is not set in a clear zone; otherwise, the slope is $1: n_{2}$, as shown in Figure 8 . Then, the earthwork volume of the highway per kilometer (set as $V$ ) is as follows:

$$
V=\frac{1}{2} \times 1000 h[(W+2 n h)+W] .
$$

The increment in the subgrade earthwork per kilometer generated by setting the RCZ is as follows:

$$
\Delta V=V_{2}-V_{1}=1000 h^{2}\left(n_{2}-n_{1}\right) \text {. }
$$

The average cost of the subgrade earthwork per cubic meter is set as $T_{0}$ yuan, so the cost of the subgrade earthwork is as follows:

$$
T=T_{0} \Delta V=1000 T_{0} h^{2}\left(n_{2}-n_{1}\right) .
$$

3.3.2. Land Requisition Costs. According to the highway land scope shown in Figure 8, the area per kilometer of the highway (set as $S$ ) is as follows:

$$
S=1000\left[W+2 n h+2 l_{1}+2\left(m_{1}+m_{2}\right) a+2 b+2 l_{3}\right] \text {. }
$$

The growth in road area per kilometer generated by setting the RCZ is as follows:

$$
\Delta S=S_{2}-S_{1}=2000 h\left(n_{2}-n_{1}\right)
$$

The actual land requisition costs in terms of construction engineering consist of opportunity costs, new resource consumption costs, and transfer payments. In the national economic evaluation, the opportunity cost and new resource consumption cost are adjusted according to the shadow price, while the transfer payment is not included in the land requisition costs, as shown in the following formula:

$$
E_{0}=\mathrm{OC}+Y=\mathrm{NB}_{0}(1+g)^{\tau+1}\left[\frac{1-(1+g)^{n}(1+i)^{-n}}{i-g}\right]+Y
$$

where $E_{0}$ is the land requisition cost, 10,000 yuan/mu; OC is the opportunity cost, 10,000 yuan/mu; $Y$ is the new resource 
TABLe 7: Statistics of economic losses caused by traffic accidents.

\begin{tabular}{|c|c|c|c|}
\hline Occupant injury level & Economic losses (10,000 yuan) & Number of accidents & Percentage (\%) \\
\hline \multirow{6}{*}{ Moderate injury } & $0 \sim 2$ & 26 & 13.98 \\
\hline & $2 \sim 4$ & 18 & 9.68 \\
\hline & $4 \sim 6$ & 54 & 29.03 \\
\hline & $6 \sim 8$ & 60 & 32.26 \\
\hline & $8 \sim 10$ & 21 & 11.29 \\
\hline & More than 10 & 7 & 3.76 \\
\hline Total & 1049 & 186 & 100 \\
\hline \multirow{6}{*}{ Disabling injury } & $0 \sim 4$ & 0 & 0.00 \\
\hline & $4 \sim 8$ & 1 & 1.02 \\
\hline & $8 \sim 12$ & 37 & 37.76 \\
\hline & $12 \sim 16$ & 36 & 36.73 \\
\hline & $16 \sim 20$ & 12 & 12.24 \\
\hline & More than 20 & 12 & 12.24 \\
\hline Total & 1372 & 98 & 100 \\
\hline \multirow{6}{*}{ Fatal injury } & $0 \sim 12$ & 0 & 0.00 \\
\hline & $12 \sim 24$ & 1 & 1.59 \\
\hline & $24 \sim 36$ & 20 & 31.75 \\
\hline & $36 \sim 48$ & 28 & 44.44 \\
\hline & $48 \sim 60$ & 10 & 15.87 \\
\hline & More than 60 & 4 & 6.35 \\
\hline Total & 2594 & 63 & 100 \\
\hline
\end{tabular}

consumption cost, 10,000 yuan/mu; $\mathrm{NB}_{0}$ is the annual net benefit; $g$ is the average annual net benefit growth rate; $\tau$ is the number of years from the base year to the engineering commencement year; $n$ is the economic evaluation period; and $i$ is the social discount rate. The land requisition cost per kilometer generated by setting the RCZ is as follows:

$$
E=0.0015 E_{0} \Delta S \text {. }
$$

3.4. Risks to Social Stability. Since the problems of land expropriation and demolition, farmers' burden, environmental damage, and social security caused by engineering construction tend to arouse social contradictions, the risk assessment of social stability should be determined before the engineering implementation. According to the relevant provisions of the Compilation Outline and Explanation of Social Stability Risk Assessment Reports of Major Fixed Asset Investment Projects (Trial; Issue and Reform Investment No. [2013] 428) issued by the National Development and Reform Commission (NDRC) of China [27], this paper adopts a comprehensive risk index method (CRIM) to evaluate the social stability risk caused by setting the RCZ. The specific steps are as follows:

(1) Through the analysis of the feasibility study report and the design data of the project, the significant risk factors of setting the RCZ are identified from the four aspects of legality, rationality, feasibility, and controllability of the engineering construction

(2) According to data analysis and questionnaire survey, the probability-impact matrix (PIM; as shown in Figure 11) is used to evaluate and predict the risk level of each risk factor
(3) Referring to the rules of social stability risk assessment and the expert experience of similar highway construction engineering projects, the weight of each risk factor is determined

(4) According to the weight and risk level of each risk factor, a comprehensive risk index of the engineering project is obtained via weighted calculation

(5) According to the comprehensive risk level, whether or not the engineering project should be implemented will be determined

PIM is also called the risk assessment matrix, which takes the possibility of the occurrence of risk factors as the abscissa and the impact degree of risk factors after the occurrence as the ordinate. It is mainly used to analyze specific risk points and determine their risk levels.

\section{Case Analysis}

Huashan south road in the Coastal Advanced Equipment Industry Cluster area in southern Zhejiang is in urgent need of renovation because of the increasing traffic volume. According to the preliminary design data of the project, the reconstructed highway adopts the design standard of a firstgrade highway with two-way six-lane traffic, a designed speed of $80 \mathrm{~km} / \mathrm{h}$, and a subgrade width of $44 \mathrm{~m}$. According to the traffic volume prediction results, the annual one-way AADT is approximately 5,000. K2+960 K16+358 are the filling sections; considering that there are structures and residential areas on the roadside, the design of the RCZ should be studied. According to the speed calculation model of the Specifications for Highway Safety Audit (JTG B05-2015) [5], the operating 


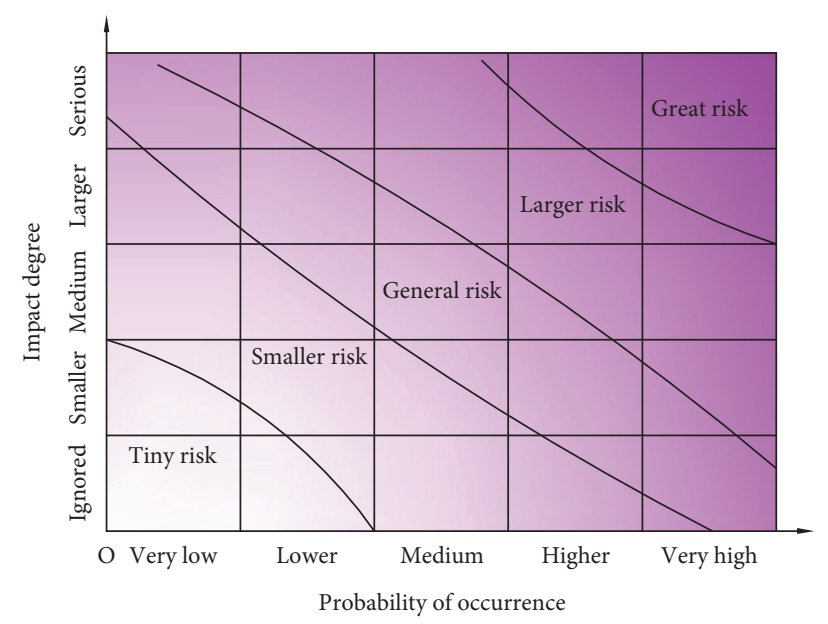

Figure 11: PIM.

TABLE 8: Results.

\begin{tabular}{|c|c|c|c|c|c|c|c|c|c|c|c|}
\hline No. & Mileage peg & $\begin{array}{c}v \\
\left(\mathrm{~km} \cdot \mathrm{h}^{-1}\right)\end{array}$ & $\begin{array}{c}R \\
(\mathrm{~m})\end{array}$ & $\begin{array}{c}w \\
(\mathrm{~m})\end{array}$ & $\begin{array}{c}h \\
(\mathrm{~m})\end{array}$ & $h / l$ & $\begin{array}{l}\text { Lower limit } \\
\text { value of } m \\
(\mathrm{~m})\end{array}$ & $\begin{array}{l}\text { Allowable } \\
\text { RCZ width } \\
(\mathrm{m})\end{array}$ & $\begin{array}{c}\text { Benefit-cost ratio } \\
\text { (benefit/cost/ } \\
10,000 \text { yuan) }\end{array}$ & $\begin{array}{l}\text { Social } \\
\text { stability } \\
\text { risk }\end{array}$ & $\begin{array}{l}\text { Setting } \\
\text { the RCZ }\end{array}$ \\
\hline 1 & $\mathrm{~K} 2+960 \sim \mathrm{K} 4+070$ & 105 & $+\infty$ & 3 & 1.65 & 0.161 & 7.48 & 10.97 & $3.18(379 / 119)$ & 0.216 & Yes \\
\hline 2 & $\mathrm{~K} 4+070 \sim \mathrm{K} 5+182$ & 99 & $+\infty$ & 3 & 1.43 & 0.166 & 6.59 & 10.97 & $1.59(196 / 123)$ & 0.216 & Yes \\
\hline 3 & $\mathrm{~K} 5+182 \sim \mathrm{K} 6+225$ & 88 & 3,900 & 3 & 1.78 & 0.223 & - & - & - & - & No \\
\hline 4 & $\mathrm{~K} 6+225 \sim \mathrm{K} 7+330$ & 88 & 3,900 & 3 & 2.23 & 0.280 & - & - & - & - & No \\
\hline 5 & $\mathrm{~K} 7+330 \sim \mathrm{K} 8+416$ & 83 & 3,500 & 3 & 2.51 & 0.315 & - & - & - & - & No \\
\hline 6 & $\mathrm{~K} 8+416 \sim \mathrm{K} 9+550$ & 70 & 3,800 & 3 & 1.63 & 0.151 & 5.41 & 10.97 & $1.13(124 / 110)$ & 0.216 & Yes \\
\hline 7 & $\mathrm{~K} 9+550 \sim \mathrm{K} 10+615$ & 75 & 3,800 & 3 & 1.34 & 0.164 & 5.79 & 10.97 & $0.66(81 / 122)$ & - & No \\
\hline 8 & $\mathrm{~K} 10+615 \sim \mathrm{K} 11+718$ & 69 & 1,800 & 3 & 1.08 & 0.136 & 5.52 & 10.97 & $0.89(87 / 97)$ & - & No \\
\hline 9 & $\mathrm{~K} 11+718 \sim \mathrm{K} 12+800$ & 67 & 2,000 & 3 & 1.89 & 0.237 & - & - & - & - & No \\
\hline 10 & $\mathrm{~K} 12+800 \sim \mathrm{K} 13+910$ & 73 & 2,000 & 3 & 1.14 & 0.143 & 5.55 & 10.97 & $2.16(224 / 103)$ & 0.216 & Yes \\
\hline 11 & $\mathrm{~K} 13+910 \sim \mathrm{K} 15+105$ & 69 & 2,000 & 3 & 1.43 & 0.179 & - & - & - & - & No \\
\hline 12 & $\mathrm{~K} 16+105 \sim \mathrm{K} 16+358$ & 69 & 1,500 & 3 & 1.05 & 0.132 & 5.78 & 10.97 & $2.00(188 / 94)$ & 0.216 & Yes \\
\hline
\end{tabular}

speed of each section is predicted. Table8 summarizes the design indexes and operating speeds of each section.

4.1. Determination of the Setting Condition for the RCZ. According to the cross-sectional design data of the project, the width of the berm, side ditch, and outer area of the side ditch are $1 \mathrm{~m}, 2 \mathrm{~m}$, and $1 \mathrm{~m}$, respectively. By referring to the provisions of the highway land scope in China's Highway Engineering Project Construction Land Index (Construction Standard [2018] 124) [26], formula (4) is used to calculate the land scope of the SCZ: $l=(63.935-44-1-2-1) /$ $2=7.9675 \mathrm{~m}$. According to the subgrade height of each section (as shown in Table 8), the calculation results show that sections $1,2,6,7,8,10$, and 12 conform to the relationship shown in formula (1). In addition, if the RCZ is set, the RCZ width should be further verified to meet the recommended width given in Section 2. According to formula (3), the allowable RCZ widths of sections 1, 2, 6, 7, 8, 10, and 12 are all larger than the corresponding lower limit widths. Among them, the recommended RCZ width in the straight section is obtained via the line interpolation method according to Table 2 .
Aimed at the above 7 sections that meet the conditions for setting the RCZ, the safety benefit calculation model and engineering cost calculation model are used to calculate the safety improvement benefit and additional engineering cost of each section brought by the RCZ and further consider whether to set the RCZ by analyzing their benefit-cost ratios.

4.2. Calculations of the Safety Benefit and Engineering Cost. In the process of the safety improvement benefit assessment, when calculating the probability of roadside accidents, the adhesion coefficient is set to 0.7 because the reconstructed road is dry asphalt pavement. In the process of engineering cost accounting, according to the relevant provisions of the Specifications for Highway Safety Audit (JTG B05-2015) [5], the slope gradient should be 1:3.5 when there is no RCZ and $1: 6$ when there is an RCZ.

According to the project feasibility report, the average earthwork cost is proposed to be $55 \mathrm{yuan} / \mathrm{m}^{3}$, so the total earthwork costs can be calculated by formula (11). Since rice is mainly planted along the road, according to the relevant regulations of the local price bureau, the annual net benefit is 
TABLE 9: Significant risk factors.

\begin{tabular}{lc}
\hline Category & Risk factors \\
\hline Legality & Policy risk \\
Rationality & Legal risk \\
Feasibility & Ecological environment risk \\
Controllability & Land requisition and demolition risk \\
& Social security risk \\
\hline
\end{tabular}

TABLE 10: Statistical results of the questionnaire survey.

\begin{tabular}{|c|c|c|c|c|}
\hline & Question & & Frequency & Percentage $(\%)$ \\
\hline \multirow{4}{*}{$\begin{array}{l}\text { Ecological environment } \\
\text { risk }\end{array}$} & \multirow{4}{*}{ What do you think is the ecological impact of setting the RCZ? } & Beneficial & 61 & 53.04 \\
\hline & & Nothing & 49 & 42.61 \\
\hline & & Harmful & 1 & 0.87 \\
\hline & & Unknown & 4 & 3.48 \\
\hline \multirow{9}{*}{$\begin{array}{l}\text { Land requisition and } \\
\text { demolition risk }\end{array}$} & \multirow{4}{*}{$\begin{array}{l}\text { Are you satisfied with the current way of land requisition and } \\
\text { demolition? }\end{array}$} & Satisfied & 90 & 78.26 \\
\hline & & Dissatisfied & 6 & 5.22 \\
\hline & & General & 19 & 16.52 \\
\hline & & Satisfied & 88 & 76.52 \\
\hline & \multirow[t]{2}{*}{ Are you satisfied with the current compensation standard? } & Dissatisfied & 7 & 6.09 \\
\hline & & General & 20 & 17.39 \\
\hline & \multirow{3}{*}{$\begin{array}{l}\text { To set the RCZ, if the land requisition and demolition continue } \\
\text { according to the current way and compensation standard, can you } \\
\text { accept it? }\end{array}$} & Yes & 89 & 77.39 \\
\hline & & No & 7 & 6.09 \\
\hline & & Unconcerned & 19 & 16.52 \\
\hline
\end{tabular}

1,106 yuan/mu, and the average annual net benefit growth rate is $6 \%$. In addition, the base year for engineering is the commencement year, so $\tau$ is set as 0 . Referring to the relevant provisions of the Economic Evaluation Methods and Parameters of Construction Projects (third edition) [28], the economic evaluation period takes 25 years, and the social discount rate is $8 \%$. In this project, new resource consumption costs mainly include elderly maintenance, endowment insurance, relocation compensation, resettlement fees, and compensation for attachments to land, whose prices are taken as 5,400 yuan/mu, 1,000 yuan/mu, 34,800 yuan/mu (adjusted by the shadow price conversion factor $1.1), 16,200$ yuan/mu, and 6,000 yuan/mu, respectively, for a total of $63,400 \mathrm{yuan} / \mathrm{mu}$. According to formulas (14) and (15), the land requisition cost can be calculated.

Table 8 shows the safety benefit and the engineering costs of the seven sections. Among them, the benefit-cost ratio of sections $1,2,6,10$, and 12 is $>1$, that is, the safety benefit is greater than the engineering cost, so they can be considered to set the RCZ. However, the risks to social stability caused by the setting of the RCZ in these sections should be further assessed.

4.3. Social Stability Risk Assessment. Combined with the construction background of the project and the construction characteristics of the RCZ, the significant risk factors of setting the RCZ are identified from the four aspects of legality, rationality, feasibility, and controllability, as shown in Table 9.

The risk level of each significant risk factor is evaluated and predicted by using the PIM as follows.
4.3.1. Policy Risk. According to the project planning, the RCZ is included in the road structure and conforms to the relevant provisions of the Specifications for Highway Safety Audit (JTG B05-2015). Therefore, the RCZ complies with the national industrial policy; the probability of policy risk is very low; and the impact degree is medium, so the risk is considered a smaller risk.

4.3.2. Legal Risk. The decision-maker of this project is the Wenzhou municipal government, and relevant external supporting documents, land preexamination, and environmental impact assessments have all passed the examination. From the perspective of legal procedure, the overall construction of this project (including the RCZ) meets the requirements of current laws and regulations, so the probability of legal risk is very low and the impact degree is medium, which is considered to be a smaller risk.

\subsubsection{Risk of the Ecological Environment and Risk of Land} Requisition and Demolition. For farmland, residential areas, and enterprises involved in land requisition and demolition of sections $1,2,6,10$, and 12 , the questionnaire survey is conducted to collect public opinion on the environmental damage, land requisition, and demolition caused by the RCZ. The entire process of public participation follows the principle of representativeness and randomness. Considering that respondents under the age of 20 and over the age of 75 have biased understandings of the interview content, the above age groups are excluded. Finally, there were 68 males and 47 females in all the collected samples. The sample distribution basically reflects the overall intention of the 
TABLE 11: Social stability risk assessment before project implementation.

\begin{tabular}{|c|c|c|c|c|c|c|c|}
\hline \multirow[b]{2}{*}{ Risk factor } & \multicolumn{7}{|c|}{ Risk level } \\
\hline & Weight & $\begin{array}{l}\text { Tiny } \\
0.04 \\
\end{array}$ & $\begin{array}{c}\text { Smaller } \\
0.16\end{array}$ & $\begin{array}{c}\text { General } \\
0.36\end{array}$ & $\begin{array}{c}\text { Larger } \\
0.64\end{array}$ & $\begin{array}{c}\text { Great } \\
1\end{array}$ & Risk index \\
\hline Policy risk & 0.14 & & $\sqrt{ }$ & & & & 0.0224 \\
\hline Legal risk & 0.13 & & $\sqrt{ }$ & & & & 0.0208 \\
\hline Ecological environment risk & 0.15 & $\sqrt{ }$ & & & & & 0.006 \\
\hline Land requisition and demolition risk & 0.37 & & & $\sqrt{ }$ & & & 0.1332 \\
\hline Social security risk & 0.11 & & $\sqrt{ }$ & & & & 0.0176 \\
\hline Public opinion risk & 0.10 & & $\sqrt{ }$ & & & & 0.016 \\
\hline$\Sigma$ & 1 & & & & & & 0.216 \\
\hline
\end{tabular}

survey group, and the location of the sample covers the area affected by the RCZ. The survey results are shown in Table 10.

As can be seen from the statistical results in Table 10, only $0.87 \%$ of all respondents believe that the setting of the RCZ is harmful to the ecological environment, so the probability of ecological environment risk is very low and the impact degree can be ignored; therefore, the risk is considered a tiny risk. Moreover, 5.22\% and 6.09\% of respondents are not satisfied with the methods of land requisition and compensation standards, respectively, which means that this part of the group cannot accept the following requisition. However, the remaining $94 \%$ of respondents are in favor of or do not oppose setting the RCZ, so the probability of land requisition and demolition risk is lower and the impact degree is larger, which is considered a general risk.

4.3.4. Social Security Risk. As the constructor has formulated a reasonable construction organization and supervision measures, strengthened close communication with the local government, and comprehensively created a safe, harmonious, and stable public security environment, the probability of a social security risk is very low, and the impact degree is larger, so this risk is considered to be a smaller risk.

4.3.5. Public Opinion Risk. Although the project has been strongly supported by the local residents, the construction of the RCZ will have a certain impact on the surrounding environment. Therefore, publicity and positive guidance are particularly important. The constructor performed a significant amount of publicity work through mainstream media and networks in the early stage, so the probability of public opinion risk is lower and the influence degree is medium. Therefore, this risk is considered a smaller risk.

Referring to the rules of some social stability risk assessments of highway construction projects and expert experience, the weight of each risk factor in the setting of the RCZ is determined. The weight and risk level of each factor are weighted to obtain the comprehensive risk index of the project, as shown in Table 11.

In general, when the comprehensive risk index is lower than 0.36 , which indicates that the social stability risk level of the project is smaller (i.e., the majority of people understand and support the project), a small number of people have opinions on the project, but effective persuasion and guidance can prevent and resolve the conflicts. As can be seen from Table 11, the social stability risk caused by setting the RCZ is 0.216 , which is a smaller risk. Therefore, sections $1,2,6,10$, and 12 are feasible for setting the RCZ.

\section{Conclusion}

This paper explores the main factors affecting the design of the RCZ width, including the shoulder width, slope gradient, braking response time, departure speed, and departure angle. PC-Crash software is used to establish the vehicle and road models to perform simulations of a vehicle entering the roadside by setting different departure speeds and curve radii. By recording the track of the vehicle after entering the roadside and measuring the lateral distance between the right front of the vehicle and the lane edge, the recommended widths of the RCZ in the straight and curved sections for different operating speeds and curve radii are given. The Fourth Edition of the RDG and China's Specifications for Highway Safety Audit (JTG B05-2015) provide the RCZ width determination method. For the straight section with fill and excavation subgrades, the Fourth Edition of the RDG provides a recommended RCZ width corresponding to different design speeds, AADT, and slope. For the curved section, it provides a correction coefficient for a curved section that is based on the horizontal curve radius, but this guide does not provide a specific calculation method. Referring to the Fourth Edition of the RDG, China's Specifications for Highway Safety Audit (JTG B05-2015) show how to determine the recommended RCZ width in the form of a graph. However, the calculation accuracy of the graphical method is inadequate, while the proposed method in this paper can accurately calculate the width of the RCZ via modeling.

Based on our previous research results and data, the probability prediction model of roadside accidents and the occupant injury risk assessment model are constructed by means of the binary logistic regression analysis, the multiple regression analysis, and the Fisher optimal segmentation algorithm, and the quantitative analysis of the probability and occupant injury risk of roadside accidents is realized.

Based on the above research results, this paper determines the setting conditions for the RCZ by considering the 
land use index, the subgrade height, and the shoulder width. A safety benefit calculation model based on AADT, the occurrence probability, and the occupant injury risk of roadside accidents is constructed, and an engineering cost calculation model is given from the two aspects of earthwork costs and land requisition costs. Thus, an RCZ design method based on the safety benefit and the engineering cost is proposed. Based on the benefit-cost ratio analysis, the CIDM is adopted to evaluate the social stability risk of the project. Finally, the research results are applied by a case analysis. This result fills in the gaps of the Fourth Edition of the RDG and China's Specifications for Highway Safety Audit (JTG B05-2015) in the setting conditions of the RCZ by first involving social stability risk into the RCZ design.

The results of this paper are helpful for reducing the occurrence and loss of roadside accidents and can provide a reference and guidance for traffic control departments and highway designers to optimize the design of roadside safety in the future. However, because the recommended width of the RCZ obtained in this paper is based on the test condition of a safety slope of 1:6, in practical engineering implementations, the RCZ width should be adjusted when another slope gradient is adopted, but their relationship is not yet clear. Therefore, the precise quantitative calculation between the RCZ width and the safety slope gradient can be further determined. Additionally, since the research results of this paper are based on simulation data, certain variables are assigned values in advance according to professional standards and experience. Moreover, the human factor cannot be considered in the simulation software, which is an important factor affecting the occurrence of roadside accidents. Therefore, validation of the results and research on roadside design involving human factors should be implemented by collecting real accident cases in the future.

\section{Data Availability}

The data used to support the findings of this study are available from the corresponding author upon request.

\section{Conflicts of Interest}

The authors declare that they have no conflicts of interest.

\section{Acknowledgments}

This study was supported by Fund for Less Developed Regions of the National Natural Science Foundation of China (No. 71861006), Guangxi Natural Science Foundation (No. 2020GXNSFAA159153), and Guangxi Science and Technology Base and Talent Special Project (No. AD20159035).

\section{References}

[1] RISER Consortium, Guidelines for Roadside Infrastructure on New and Existing Roads. Roadside Infrastructure for Safer European Roads, Deliverable 6. 5th Research Framework Programme "Growth", European Commission, Brussels, Belgium, 2005.
[2] Federal Highway Administration (FHWA), Roadway Departure Safety, Federal Highway Administration (FHWA), Washington, DC, USA, 2018.

[3] Traffic Management Bureau of the Ministry of Public Security (TMBMPS), Road Traffic Accident Statistical Annual Report, TMBMPS, Beijing, China, 2018.

[4] American Association of State Highway and Transportation Officials (AASHTO), Roadside Design Guide, American Association of State Highway and Transportation Officials (AASHTO), Washington, DC, USA, 4th edition, 2011.

[5] Ministry of Transport of the People's Republic of China (MTPRC), Specifications for Highway Safety Audit (JTG B052015), Ministry of Transport of the People's Republic of China (MTPRC), Beijing, China, 2015.

[6] Michigan Department of Transportation (MDOT), Road Design Manual, Michigan Department of Transportation (MDOT), Cadillac, MI, USA, 2011.

[7] C. R. Sax, T. H. Maze, R. R. Souleyrette, N. Hawkins, and A. L. Carriquiry, "Optimum urban clear zone distance," Transportation Research Record, vol. 2195, no. 1, pp. 27-35, 2010.

[8] X. Fan and Y. Xing, "Study on the width design of highway roadside clear zone considering tolerance concept," Journal of Transportation Engineering and Information, vol. 11, no. 4, pp. 49-54, 2013.

[9] K. W. Ogden, Safer Roads: A Guide to Road Safety Engineering, Ashgate Publishing Company, Burlington, Canada, 1996.

[10] C. Jurewicz and V. Pyta, "Effect of clear zone widths on runoff-road crash outcomes," in Proceedings of the 2010 Australasian Road Safety Research, Policing and Education Conference, pp. 1-12, Canberra, Australia, 2010.

[11] C. D. Fitzpatrick, S. Samuel, and M. A. Knodler Jr., "Evaluating the effect of vegetation and clear zone width on driver behavior using a driving simulator," Transportation Research Part F: Traffic Psychology and Behaviour, vol. 42, pp. 80-89, 2016.

[12] C. D. Fitzpatrick, C. P. Harrington, M. A. Knodler Jr., and M. R. Romoser, "The influence of clear zone size and roadside vegetation on driver behavior," Journal of Safety Research, vol. 49, pp. 97-104, 2014.

[13] American Association of State Highway and Transportation Officials (AASHTO), Roadside Design Guide, American Association of State Highway and Transportation Officials (AASHTO), Washington, DC, USA, 1998.

[14] F. D. B. de Albuquerque, D. L. Sicking, R. K. Faller, and K. A. Lechtenberg, "Evaluating the cost-effectiveness of roadside culvert treatments," Journal of Transportation Engineering, vol. 137, no. 12, pp. 918-925, 2011.

[15] E. Ayati and M. Shahidian, "Safety and cost-effectiveness of clear zones in Iran," Civil Engineering Innovation, vol. 2, no. 1, pp. 37-46, 2007.

[16] E. Ayati and M. Shahidian, "Decision aid for allocation of transportation funds to roadside safety enhancement," Iranian Journal of Science \& Technology Transaction B Engineering, vol. 31, no. 2, pp. 143-154, 2007.

[17] C. Roque and J. L. Cardoso, "SAFESIDE: a computer-aided procedure for integrating benefits and costs in roadside safety intervention decision making," Safety Science, vol. 74, pp. 195-205, 2015.

[18] G. Cheng, R. Cheng, Y. Pei, and L. Xu, "Probability of roadside accidents for curved sections on highways," Mathematical Problems in Engineering, vol. 2020, Article ID 9656434, 18 pages, 2020.

[19] G. Cheng, R. Cheng, L. Xu, and W. Zhang, "Risk assessment of roadside accidents based on occupant injuries analysis," 
Journal of Jilin University (Engineering and Technology Edition), vol. 51, 2020.

[20] Ministry of Transport of the People's Republic of China (MTPRC), Technical Standard of Highway Engineering (JTG B01-2014), MTPRC, Beijing, China, 2014.

[21] L. Li, X. Zhu, and Z. Ma, "Driver brake reaction time under real traffic risk scenarios," Automotive Engineering, vol. 36, no. 10, pp. 1225-1229, 2014.

[22] Standardization Administration of China, Identification for the Speed of Vehicle Involved in Road Traffic Accident (GB/T 33195-2016), Standardization Administration of China, Beijing, China, 2016.

[23] T. F. Zou, Q. Liu, A. M. Zha, C. Simms, and T. Chen, "New observations from real-world vehicle-pedestrian collisions in reducing ground related injury by controlling vehicle braking," International Journal of Crashworthiness, vol. 2020, Article ID 1827848, 2020.

[24] H. Wu, Y. Han, D. Pan et al., "The head AIS 4+ injury thresholds for the elderly vulnerable road user based on detailed accident reconstructions," Frontiers in Bioengineering and Biotechnology, vol. 9, no. 6, Article ID 682015, 2021.

[25] Ministry of Transport of the People's Republic of China (MTPRC), Design Specification for Highway Alignment (JTG D20-2017), MTPRC, Beijing, China, 2017.

[26] Ministry of Land and Resources of the People's Republic of China (MLRPRC), China's Highway Engineering Project Construction Land Index (Construction Standard [2018] 124), MLRPRC, Beijing, China, 2018.

[27] National Development and Reform Commission (NDRC), Compilation Outline and Explanation of Social Stability Risk Assessment Reports of Major Fixed Asset Investment Projects (Trial) (Issue and Reform Investment No. [2013] 428), NDRC, Beijing, China, 2013.

[28] National Development and Reform Commission (NDRC), Economic Evaluation Methods and Parameters of Construction Projects, NDRC, Beijing, China, 3rd edition, 2006. 